\title{
Notes on the vocalizations of Asian Brown Flycatcher (Muscicapa dauurica)
}

Peter Boesman

In the following we briefly analyze and compare voice of the different races of Asian Brown Flycatcher (Muscicapa dauurica). We also try to quantify the extent of any vocal differences using the criteria proposed by Tobias et al. (2010), as a support for taxonomic review.

We have made use of sound recordings available on-line from Xeno Canto (XC) and Macaulay Library (ML).

Our main interest is to compare voice of recently described M. sodhii (Harris 2014) with other related taxa. Few recordings of song are available for many taxa in the genus Muscicapa (and about 50\% of ML recordings for Muscicapa are restricted). An overview per race:

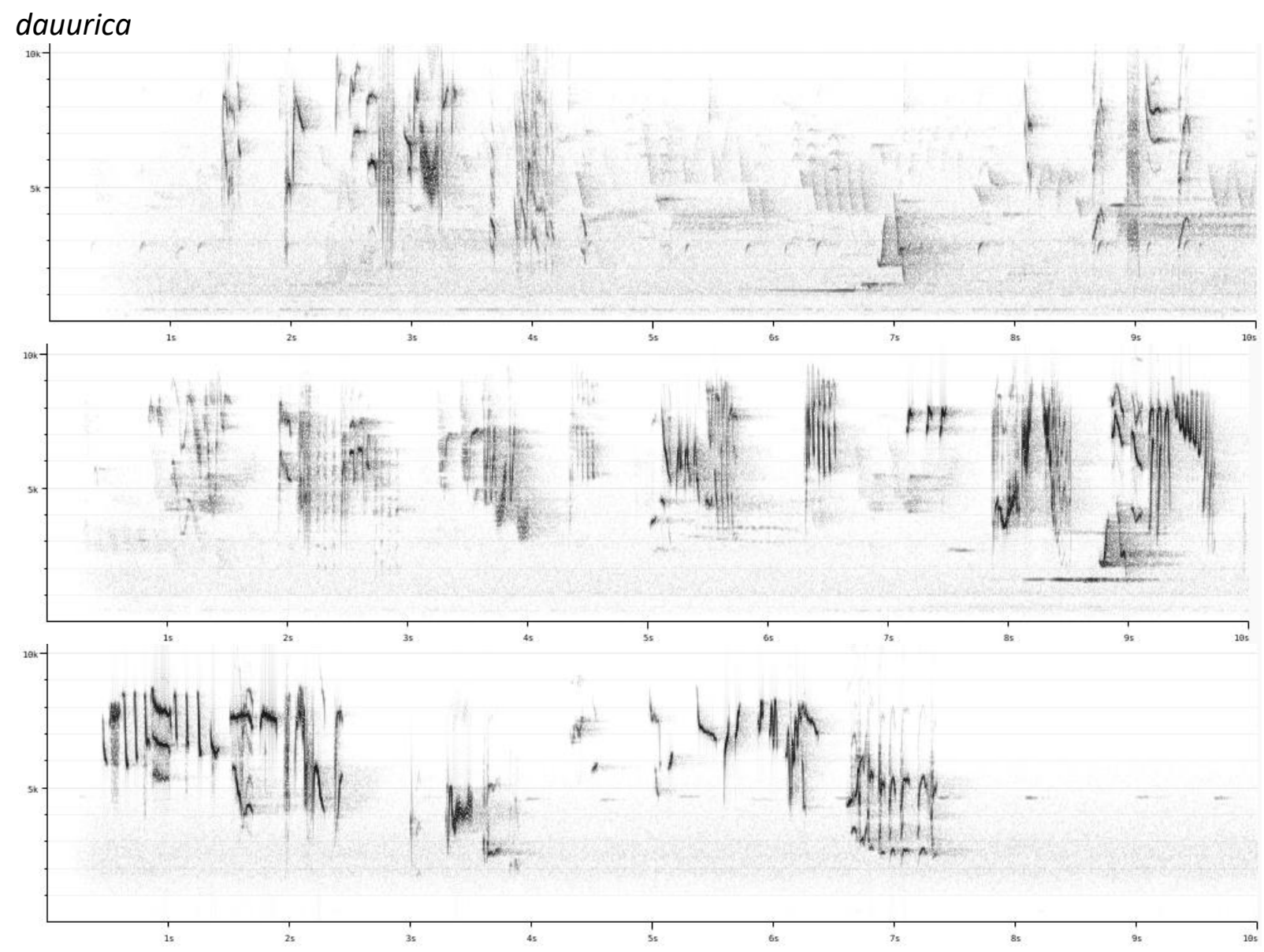




\section{HANDBOOK OF THE \\ BIRDSPF THE WORLD}

\section{ORNITHOLOGICAL NOTES}
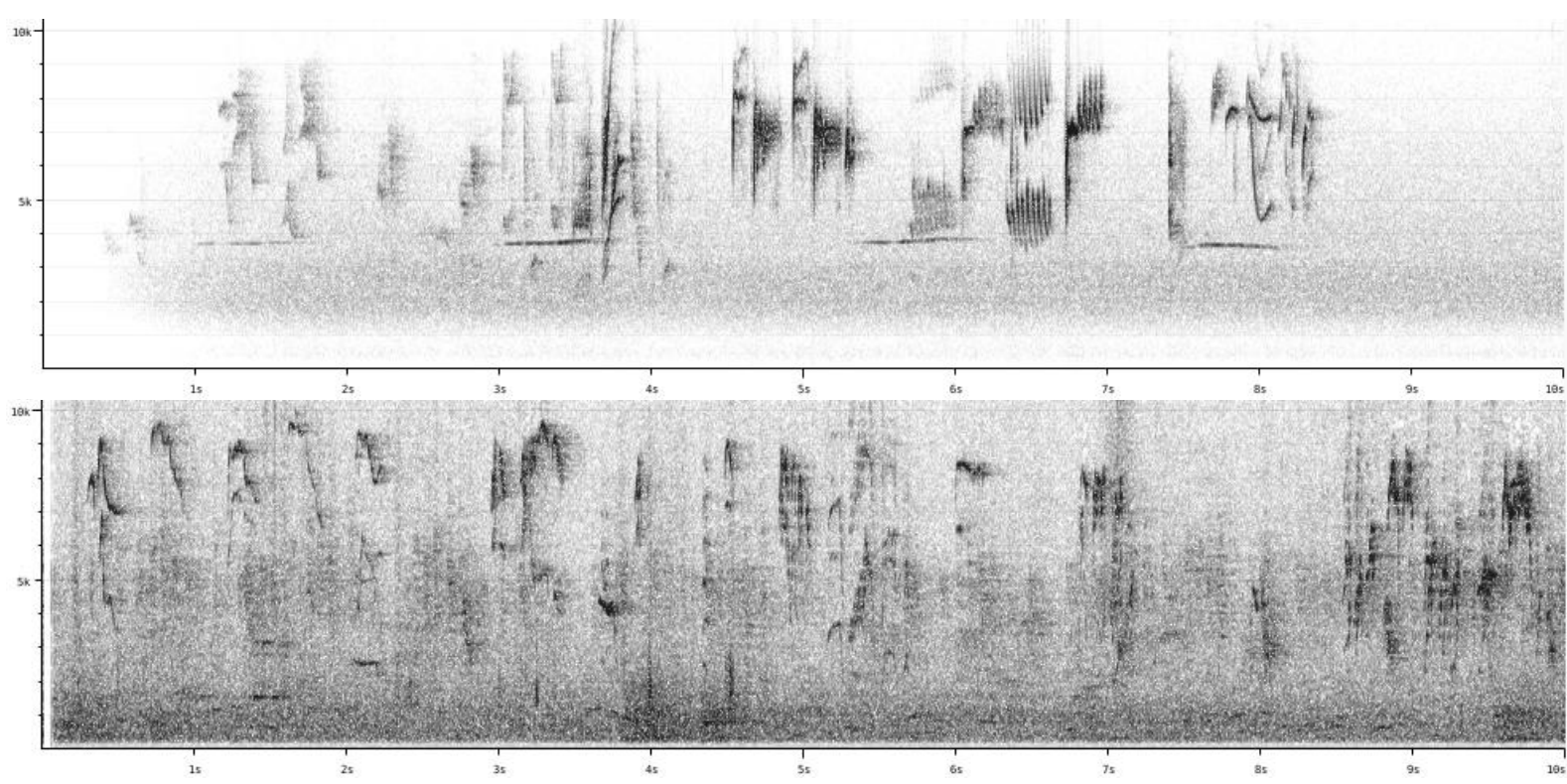

Max. freq. $10.5 \mathrm{kHz}$, most notes in range $2.5-9.5 \mathrm{kHz}$

sodhii $(n=1)$

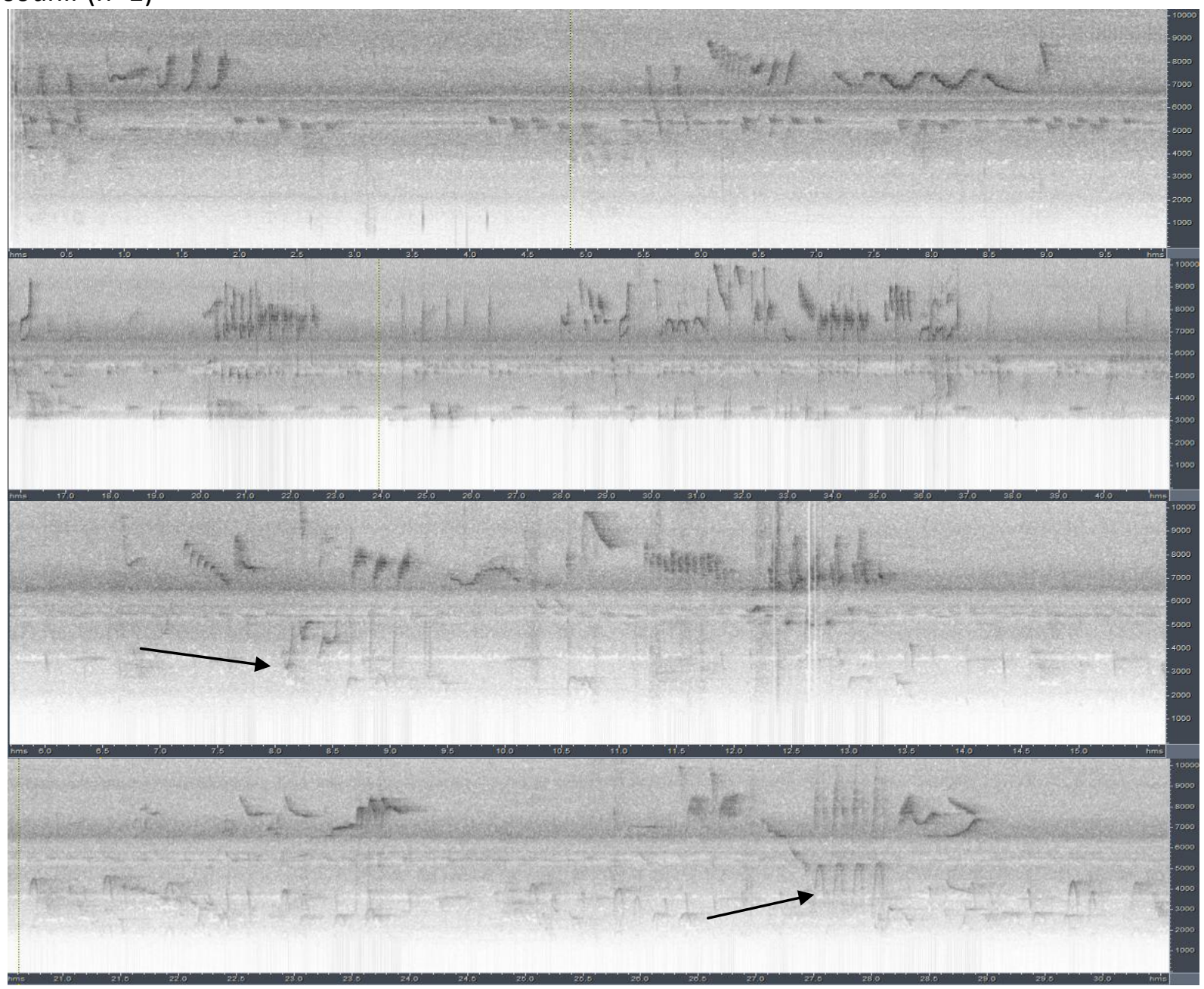



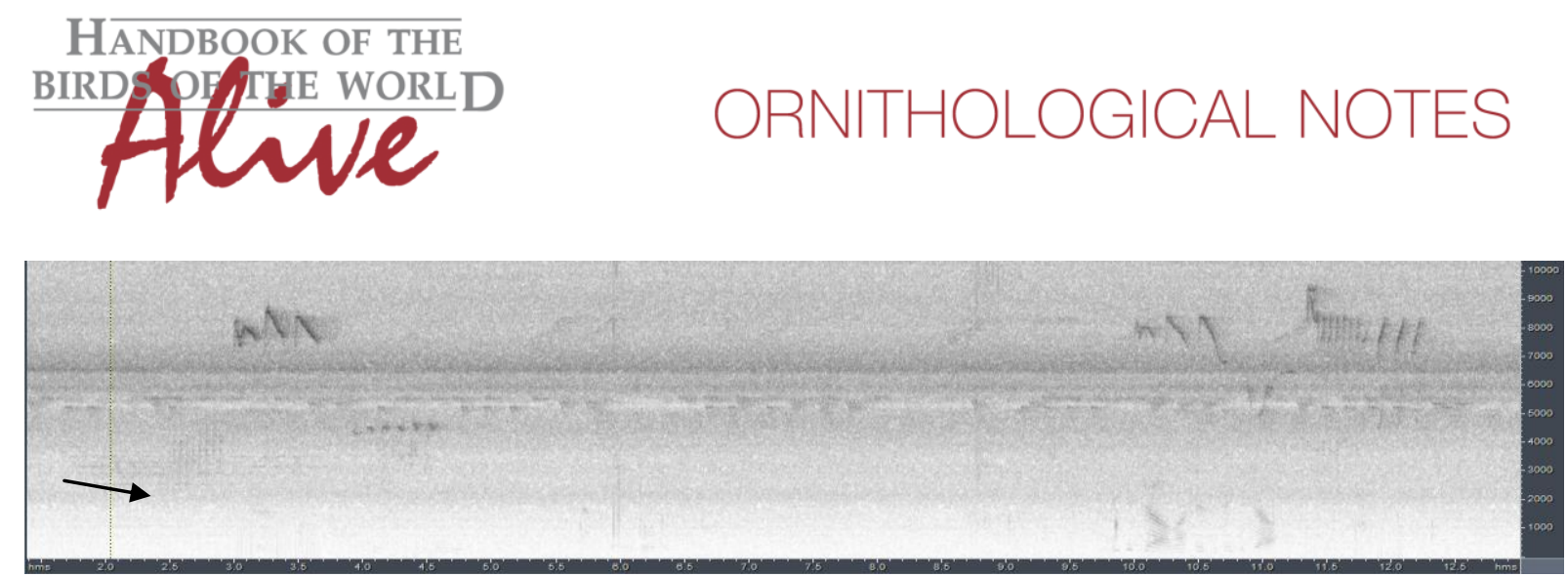

Max. freq. $10 \mathrm{kHz}$, most notes in range $5-9.5 \mathrm{kHz}$, some down to $2.2 \mathrm{kHz}$ (!)

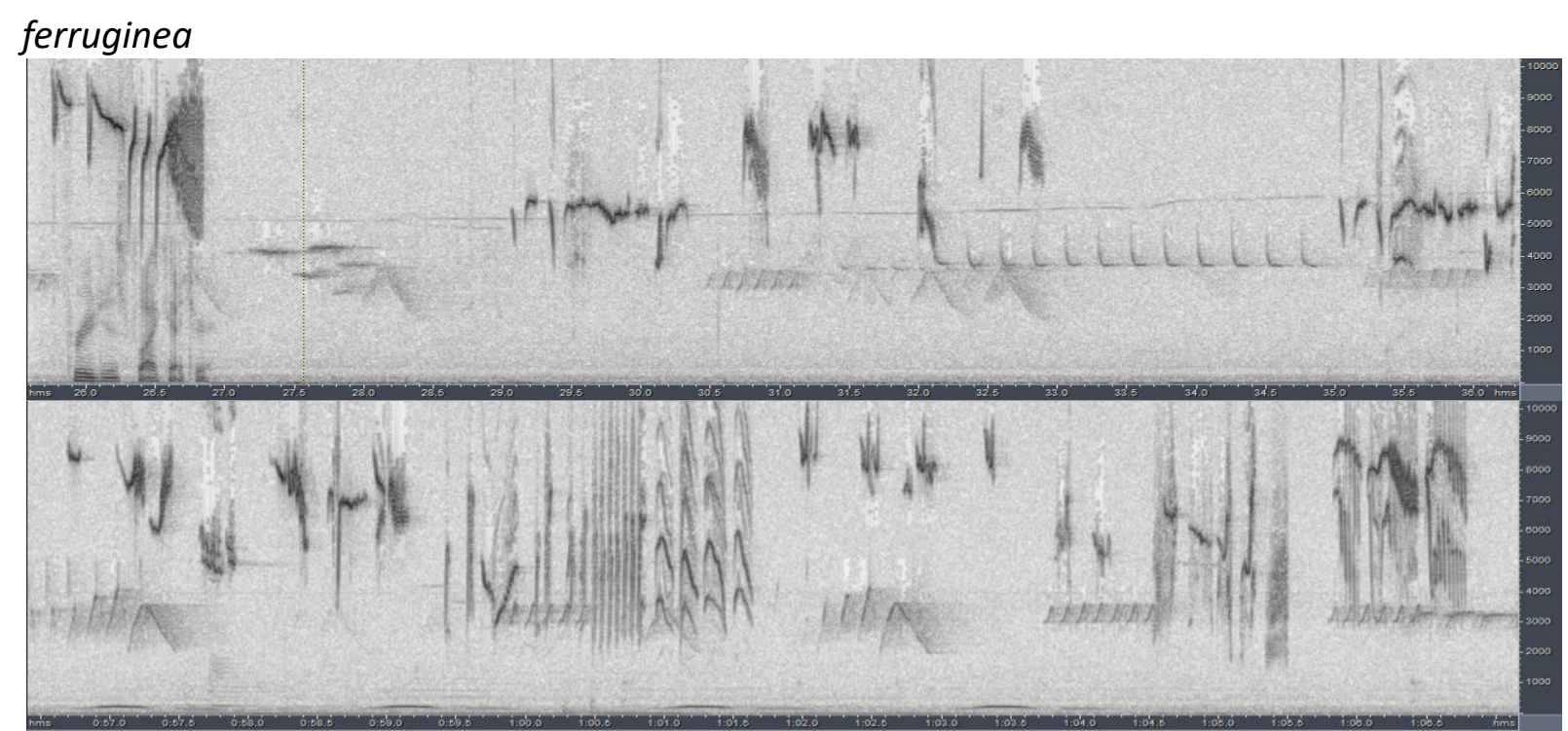

Max. freq. exceeds $10 \mathrm{kHz}$, most notes in range $3-10 \mathrm{kHz}$

Main vocal difference seems to be that notes in recording of sodhii song are mainly above $5 \mathrm{kHz}$ and have a narrower frequency range.

More detailed measurements are given in Table 8 by Harris et al. (2014), leading to the conclusion that main vocal difference between soddhi and other Muscicapa taxa are maximum note frequency, minimum note frequency and frequency of maximum power. This being said, we have the following critical remarks about the vocal data by Harris et al.: * vocal difference is based on a single individual of sodhii, and comparison with other taxa is also based on just 1-3 individuals/taxon. Given that at least $M$. dauurica is known to mimic (Japan), this is rather tricky. A Principal Component Analysis based on just so few samples would seem to be nothing more than a theoretical statistical exercise.

* measurements of sodhii recordings: the lowest frequency Harris et al. measured was

$5.75 \mathrm{kHz}$. They seem to have 'overlooked' quite a few lower-pitched notes, the lowest I found reaching $2.2 \mathrm{kHz}$, as indicated by arrows on above sonograms (not facilitated by the fact that at least some recordings were heavily filtered to mute all sound below $3 \mathrm{kHz} . .$. !, with possible additional high pass filtering with cut-off frequency as high as $6.5 \mathrm{kHz}$ ??). The statement that min. freq. of sodhii is much higher thus becomes really questionable.

* It should be said that in the case of poor quality recordings, obviously the fainter parts of song can become almost invisible on a sonogram (especially with high contrast settings as in Fig. 5 of the aforementioned paper). E.g. the last sonogram above of dauurica also shows mainly the high-pitched frequencies (despite having low contrast settings). 

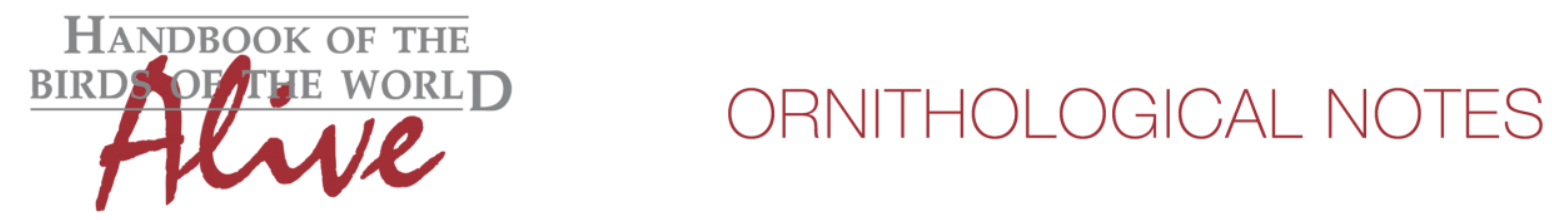

* measurements of other taxa: I only checked maximum frequency for dauurica (Table 8 gives max. freq. $8.7 \mathrm{kHz}$, above examples: up to $10.5 \mathrm{kHz}$ ) and ferruginea (Table 8 gives max. $9.2 \mathrm{kHz}$, above examples $10.1 \mathrm{kHz}$ ). Max. freq. for the recording of sodhii thus falls within the range of both dauurica and ferrugunea

* If min. and max. freq. are in the same range, then obviously frequency range (bandwidth) of song is also similar.

Etc.

As an additional remark, we should be aware that the race of $M$. dauurica geographically closest to sodhii is umbrosa from NE Borneo, of which apparently there are no recordings of song available.

While there is a clear indication that song of sodhii has relatively more high-pitched notes with a fairly narrow frequency range, caution is needed as this is based on song of a single individual. Furthermore, measurements of the sodhii recordings were definitely not flawless (!).

If more recordings confirm that indeed a larger \% of notes are above $5 \mathrm{kHz}$, this could lead to a vocal score of about 2-3 vs related Muscicapa taxa by application of Tobias criteria.

This note was finalized on 26th July 2016, using sound recordings available on-line at that moment. We would like to thank in particular the sound recordists who placed their recordings for this species on XC and AVoCet, in particular Pamela Harrison/Bert Harris for the recording from Sulawesi of race sodhii.

\section{References}

Harris, J.B.C., Rasmussen, P.C., Yong, D.L., Prawiradilaga, D.M., Putra, D.D., Round, P.D. \& Rheindt, F.E. (2014). A new species of Muscicapa flycatcher from Sulawesi, Indonesia. PLOS ONE 9(11): e112657.

Tobias, J.A., Seddon, N., Spottiswoode, C.N., Pilgrim, J.D., Fishpool, L.D.C. \& Collar, N.J. (2010). Quantitative criteria for species delimitation. Ibis 152(4): 724-746.

\section{Recommended citation}

Boesman, P. (2016). Notes on the vocalizations of Asian Brown Flycatcher (Muscicapa dauurica). HBW Alive Ornithological Note 410. In: Handbook of the Birds of the World Alive. Lynx Edicions, Barcelona. (retrieved from http://www.hbw.com/node/1253808 on 4 December 2016). 